\title{
A Qualitative Research Perspective on BPM Adoption and the Pitfalls of Business Process Modeling
}

\author{
Monika Malinova and Jan Mendling \\ Institute for Information Business, Wirtschaftsuniversität Wien, Austria \\ \{monika.malinova, jan.mendling\} @wu.ac.at
}

\begin{abstract}
Business Process Management (BPM) is used by organizations as a method to increase awareness and knowledge of business processes. Although many companies adopt BPM, there is still a notable insecurity of how to set it up in the most effective way. A considerate amount of research concerning partial aspects of BPM adoption has been done, such as the pitfalls of business process modeling. However, up until now hardly any empirical research has been conducted that aims at validating them. In this paper we address this research gap by conducting eleven in-depth interviews with BPM experts from various companies. We use the Grounded Theory approach to qualitatively analyze the data. Our contribution is twofold. First, we derive a conceptual framework showing the insights of BPM adoption by organizations. Second, we use the evidence from the interviews to discuss the pitfalls of business process modeling and show the countermeasures that are taken by companies.
\end{abstract}

Keywords: BPM Adoption, Business Process Modeling Pitfalls.

\section{Introduction}

Business process management (BPM) is adopted by an increasing number of companies for achieving different goals, from business-oriented ones such as performance improvement to system-oriented ones like process automation. Although BPM as a discipline has been established already in the 1990s, there is still a notable insecurity of how to set up BPM in a company in the most effective way. Partially, this fact is explained with the diversity of scenarios in which BPM is introduced. Furthermore, the intertwining of BPM with various strategic and operational parts of the company makes BPM adoption a complex topic to study.

Up until now, there have been different contributions to research focusing on partial aspects of BPM adoption. Business process redesign is one important perspective of BPM adoption, being summarized in Kettinger et al. [1] and supported by best practice [2]. Also success factors of business process modeling have been identified with a focus on individual projects [3]. There is also a list of business process modeling pitfalls, which address a set of important issues of general BPM adoption. While a subset of these pitfalls directly relate to the adoption question, there is currently hardly any empirical research reported that aims at validating them. 
In this paper, we approach the gap of dedicated empirical research on BPM adoption as a starting point. We took a Grounded Theory approach and conducted a set of interviews with BPM experts from adopting companies. Our contribution is a conceptual model that helps to understand BPM adoption in more detail. Specifically, we use the evidence from the interviews to discuss the pitfalls of business process modeling. Our discussion shows the validity of the pitfalls and illustrates countermeasures that are taken by companies.

The paper is structured as follows. Section 2 discusses the background of our research. It introduces the essential concepts of BPM and the pitfalls being identified by Rosemann. Section 3 describes our research design based on Grounded Theory accompanied with demographics on the interview partners. Section 4 presents our findings. First, the conceptual model is discussed. Second, its relationship to the pitfalls is investigated. Section 5 concludes and gives an outlook on future research.

\section{Background}

There are many studies focusing on the success factors concerning enterprise information systems [4]. Some of them found that for an organization to ensure a successful enterprise system implementation, they must pay sufficient attention to BPM [5]. To achieve BPM success, it is important to understand the organizational context [6]. Indulska et al. suggests that while academics mainly research on the issues related to the development and evaluation of artifacts, practitioners are interested in the purpose and adoption of BPM [7]. However, this latter issue is not getting enough research coverage though being of great importance for practitioners.

Several studies attempt to identify the capabilities organizations should adopt in order to support their BPM initiative. For instance, Bandara binds the concept of success to its context of BPM adoption [8]. The study illustrates that a process modeling project is successful if it is effective, i.e. fulfilling its objectives, and efficient, i.e. the process modeling activities are completed with the allocated resources [8]. According to Trkman, BPM should translate a firm's strategy into specific requirements and enable the execution of the strategy [9]. Hence, success could be defined as the resulting status of when the intended goals of the BPM initiative are met to a satisfactory level [10].

However, BPM by itself is not trivial to implement, as there are various aspects that need to be considered for it to bring beneficial outcomes. As much as the business process modeling success factors have been studied, there are also studies illustrating the most common pitfalls for organizations, potentially leading to BPM failure altogether. The lack of alignment between strategy and BPM projects is one of the identified failure causes when adopting BPM [9]. Beyond that, organizations tend to spend a lot of time on modeling their processes in terms of scope and depth [11], neglecting issues like selecting the right processes to model, deciding on the required level of detail, or choosing an appropriate framework. In addition it has been argued that companies often underestimate understanding issues of elaborated modeling techniques [11]. For that reason, BPM is criticized as being 
time-consuming and not delivering sufficient value [11]. Therefore, it is important to scope the role of BPM in an organization appropriately [11].

The purpose of the pitfalls suggested by Rosemann was to increase the awareness of the most common mistakes organizations can make when implementing a BPM initiative $[11,12]$. However, up until now, hardly any attempt has been made to evaluate them systematically. It is important for such to be based on empirical research, rather than on review of literature. For that reason, we not only focus on reasons and consequences of BPM adoption, but also on how organizations are dealing with potential pitfalls.

\section{$3 \quad$ Methodology}

For this paper, we utilized a qualitative research approach. This approach is advised for emerging research topics in which a small amount of previous studies has been conducted [13, 14]. It involves a purposeful description, explanation, and interpretation of collected data [15] and permits an in-depth investigation of the subject matter [16].

\subsection{Data Collection}

We conducted eleven semi-structured in-depth interviews with BPM experts from organizations from various industries. The BPM experts are employees involved in all stages of the BPM implementation. First, an interview guideline was developed, with questions relating to the BPM initiative. All interviews followed the same structure and were conducted in German. The interviews took place between September 2011 and February 2012. Because of the open nature of semi-structured interviews, the interviews ended up in an open discussion on perceived drivers and consequences of BPM. The amount of time for each interview ranged from 30-120 minutes, depending on the availability of the BPM expert from the respective organization.

Table 1. Interview Participants

\begin{tabular}{|l|l|l|l|l|l|}
\hline ID & \multicolumn{1}{|c|}{ Industry } & $\begin{array}{c}\text { Company } \\
\text { Size }\end{array}$ & $\begin{array}{c}\text { Years of } \\
\text { BPM }\end{array}$ & \multicolumn{1}{|c|}{$\begin{array}{c}\text { Number of } \\
\text { Processes }\end{array}$} & $\begin{array}{c}\text { Documented } \\
\text { Processes }\end{array}$ \\
\hline I1 & Service/Retail & 93 & Not known & $\sim 1000$ & $\sim 20$ \\
\hline I2 & Service/Retail & 740 & Not known & 400 & Not known \\
\hline I3 & Service/Medical & $\sim 21000$ & Not known & Not known & Not known \\
\hline I4 & Insurance & 881 & Not known & Not known & 242 \\
\hline I5 & Service/Energy & 313 & 1 & Not known & Not known \\
\hline I6 & Consulting & $\sim 4300$ & 1 & $>150$ & $\sim 80$ \\
\hline I7 & Service/Retail & $\sim 100$ & 3 & $\sim 100$ & $\sim 50$ \\
\hline I8 & Service/Retail & $\sim 1000$ & 3 & Not known & 120 \\
\hline I9 & Insurance & $\sim 5900$ & 8 & Not known & $\sim 350$ \\
\hline I10 & Consulting & 75 & Not known & Not known & Not known \\
\hline I11 & Consulting & $\sim 160$ & Not known & Not known & Not known \\
\hline
\end{tabular}


The questions were classified into the following three different categories: Process documentation (e.g. How do you document your processes?), Process identification (e.g. How do you decide what processes need to be modeled?) and Modeling guidelines (e.g. What does the modeling guideline contain?). We encountered organizations that find themselves in any of the phases of the BPM lifecycle.

\subsection{Data Analysis}

The qualitative analysis of the interviews was done using Grounded Theory as defined by Glaser and Strauss in 1967. This method supports inductive discovery of a theory grounded in the data [18]. The initial theory has been divided into two, namely Glaserian and Straussian approach. For this study we chose to follow the Straussian approach as it enables systematic analysis of the data collected from the interviews to unveil the essential relationships, consequently building a theory [18].

The data analysis was done in three steps consisting of three types of coding: open, axial and selective, respectively. Open coding is the process of examining, conceptualizing, and categorizing the data [18]. Conceptualizing is the first step we did. This was done by going through the interview data, giving each sentence or paragraph a discrete name representing the phenomenon. Next, we grouped the derived concepts that we found to point to the same phenomenon. To keep track of the concepts, categories, and the relationships, we used the specialized qualitative analysis software ATLAS.ti. Axial coding is a set of procedures where connections between the categories are derived [18]. This is done by utilizing a coding paradigm involving Causal Conditions, Phenomenon, Actions and Strategies, and Consequences (see Figure 1). This stage of analysis assigns accordingly the concepts derived from the open coding to each category offered by the coding paradigm [18]. Thus, if a category identifies the reasons for BPM adoption, this category turns into a subcategory of the main category Causal Conditions. Selective coding is the process of selecting and focusing on a core category, where a core category is the central phenomenon around which all other categories are integrated [18]. This phase is aligned around the conceptualization of a descriptive story about the central phenomenon of this study [18]. As a result we derived a conceptual framework explaining the phenomenon of BPM adoption.

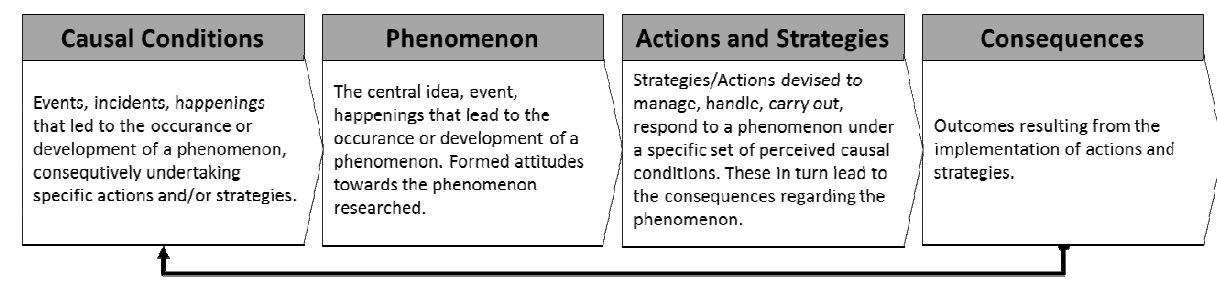

Fig. 1. Coding paradigm (adopted from [8]) 


\section{$4 \quad$ Research Findings}

The findings of our research are twofold. First, based on the concepts and categories obtained from the qualitative data analysis with Grounded Theory a conceptual framework was created. The framework provides insights into the reasons for BPM adoption, the actions organizations carry out for its implementation, as well as the subsequent consequences. Second, we use the concepts and categories from the framework along with some insights from our interview material and reference them accordingly to discuss some of the pitfalls suggested by Rosemann [11, 12]. As a result we reveal the perceptions of organizations about the underlying meaning of the respective pitfalls and the manner they avoid or resolve them.

\subsection{Conceptual Framework for BPM Adoption}

The BPM adoption conceptual framework as shown in Figure 2 has been aligned with the coding paradigm suggested by the Straussian Grounded Theory approach. Thus, the concepts were organized in the four predefined categories, each tied to the next in a sequence. During the coding of the interview material we identified the reasons that trigger organizations to adopt BPM. In addition, these reasons contribute to the organizations forming their own view about the phenomenon or an aspect thereof i.e. BPM adoption as means of a modeling language. This successively triggers the actions and strategies they undertake for the BPM implementation. As a result of the BPM adoption, organizations are faced with a set of consequences which could in turn generate further reasons for BPM adoption.

\begin{tabular}{|c|c|c|c|c|}
\hline $\begin{array}{l}\text { Reasons for BPM } \\
\text { Adoption }\end{array}$ & & \multicolumn{2}{|c|}{ Actions and Strategies } & $\begin{array}{l}\text { Outcome of BPM } \\
\text { Adoption }\end{array}$ \\
\hline $\begin{array}{l}\text { Understanding of } \\
\text { Procosses }\end{array}$ & & Modeling Language & Process Start/tnd & Understanding of \\
\hline $\begin{array}{l}\text { - Increase process } \\
\text { famillarlzation }(2 ; 2) \\
\text { - Train old/new } \\
\text { employees }(1 ; 2)\end{array}$ & & $\begin{array}{l}\text { - } \operatorname{BPMN}(10 ; 38) \\
\text { - } \operatorname{EPC}(2 ; 5) \\
\text { UMLL }(2 ; 3) \\
\quad \text { Modelers } \\
\end{array}$ & $\begin{array}{l}\text { - Depending on } \\
\text { stakeholders involved }\{4 ; 4\} \\
\text { - With customer } \\
\text { order/satisfaction }(4 ; 4)\end{array}$ & $\begin{array}{l}\text { - Proress familiarization }(6 ; 6) \\
\text { - Process manual for }(1 \text { aining } \\
\text { old/new emplnyees }(5 ; 6) \\
\text { - Prucess awdreriess }(1 ; 1)\end{array}$ \\
\hline $\begin{array}{l}\text { - Increase process } \\
\text { awdar eness }(1 ; 1) \\
\end{array}$ & & $\begin{array}{l}\text { - Employees }(5 ; 5) \\
\text { - Modeling experts \& }\end{array}$ & \begin{tabular}{|l|l|} 
Process Model \\
Representatlon
\end{tabular} & $\begin{array}{l}\text { Performance of } \\
\text { Processes }\end{array}$ \\
\hline $\begin{array}{l}\text { Performance of } \\
\text { Processes }\end{array}$ & & $\begin{array}{l}\text { - Modeling experts }(2 ; 2) \\
\text { - External consultants }(1 ; 1)\end{array}$ & $\begin{array}{l}\text { End-to-end Representation; } \\
\text { - Process type ( } 6 ; 9)\end{array}$ & - Process optimization $(5 ; 7)$ \\
\hline $\begin{array}{l}\text { - Increase process } \\
\text { standardization (6;11) }\end{array}$ & $\begin{array}{l}\text { Attitudes } \\
\text { towards BPIM }\end{array}$ & Modelling Guldellnes & $\begin{array}{l}\text { Based on department } \\
\text { involvement }(2 ; 3)\end{array}$ & $\begin{array}{l}\text { - Process standardization (4;4 } \\
\text { - Clear customer solution }\end{array}$ \\
\hline $\begin{array}{l}\cdot \text { Identification of process } \\
\text { wcakncsscs }(5 ; 6) \\
\cdot \text { Increase process } \\
\text { optimization }(3 ; 5) \\
\text { - Increase process quality } \\
(2 ; 4)\end{array}$ & $\begin{array}{l}\text { as means of: } \\
\text { - Modeling } \\
\text { guidelines }(6 ; 7) \\
\text { - Modeling } \\
\text { language }(4 ; 8)\end{array}$ & $\begin{array}{l}\text { - Process model layout }(8 ; 10) \\
\text { - Elements }(8 ; 9) \\
\text { - Roles }(2 ; 2) \\
\text { - Labels }(2 ; 2) \\
\text { - Additional elements }(1 ; 1)\end{array}$ & $\begin{array}{l}\text { - Based on process } \\
\text { complexity }(2 ; 2) \\
\text { Decomposition of Processes: } \\
\text { - Based on number of } \\
\text { elements }(5 ; 6)\end{array}$ & $\begin{array}{l}\text { approach }(2 ; 4) \\
\text { - Easier finding process } \\
\text { weaknesses }(2 ; 2) \\
\text { - Efficient adaption/utilizat on } \\
\text { of resources }(2 ; 2)\end{array}$ \\
\hline Increase process efficiency & & Process Identification & :omplex & Control of Processes \\
\hline Control of Processes & & $\begin{array}{l}\text { - Routine processes }(11 ; 23) \\
\text { - Processes for }\end{array}$ & $\begin{array}{l}\text { - Based on stakeholders } \\
\text { involvement }(4 ; 5)\end{array}$ & $\begin{array}{l}\text { - Process transparency }(6 ; 7) \\
\text { - Easler roles and }\end{array}$ \\
\hline $\begin{array}{l}\text { - Nllocate roles and } \\
\text { responsibilities }(4 ; 6)\end{array}$ & & $\begin{array}{l}\text { optimization }(6 ; 9) \\
\text { - Processes defining the }\end{array}$ & \begin{tabular}{|c|}
$\begin{array}{c}\text { Methods for ensuring } \\
\text { process quality }\end{array}$ \\
\end{tabular} & $\begin{array}{l}(4 ; 5) \\
\text { Process automation }(2 \cdot 2)\end{array}$ \\
\hline $\begin{array}{l}\text { - Increase process } \\
\text { transparency (4;5) } \\
\text { - Shape the managenent } \\
(4 ; 4) \\
\text { - Demand for new IT } \\
\text { systerl }(2 ; 2) \\
\text { - Increase process } \\
\text { governance }(2,2) \\
\end{array}$ & & $\begin{array}{l}\text { - Processes for an IT } \\
\text { system }(3 ; 4) \\
\text { - According to department } \\
\text { need }(2 ; 3) \\
\text { - According to project } \\
\text { demand }(2 ; 3)\end{array}$ & $\begin{array}{l}\text { - Steps for process } \\
\text { approval }(7 ; 8)\end{array}$ & \\
\hline
\end{tabular}

Fig. 2. BPM Adoption Conceptual Framework 
The relative importance of each concept in the framework can be assessed by the number of companies that mentioned them, as well as the number of times each interviewee mentioned them. Therefore, they could be used as a preliminary indicator for relevance. This number is shown in brackets next to each concept (e.g. Category: Reasons for BPM Adoption; Subcategory: Performance of Processes; concept: Identification of process weaknesses $(5 ; 6))$. The first number reflects the number of interviews the respective concept was mentioned in, whereas the second number indicates the number of occurrences this concept had in all interviews.

\subsubsection{Reasons for BPM Adoption}

Each organization has particular motives for undertaking a BPM initiative. Our analysis unveiled a list of reasons for organizations to start modeling their processes. The reasons for BPM adoption presented in Figure 2 reflect the expectations upon the results BPM will yield. These can be classified into three categories: reasons concerned with understanding of processes, performance of processes and control of processes.

More than half of our interviewees pointed out the importance of standardizing their current processes. This need is "because we have a large amount of people employed and more departments...therefore we wanted to standardize the processes so that every employee applies the process the same way as the others"(I7). Moreover, five companies indicated the necessity of identifying process weaknesses, arguing that without BPM the course of doing that would have been more difficult or even impossible: “...it is much simpler to find the cutting points”(I6).

Whereas understanding and performance of processes has proved to be important, the issue of control was also mentioned as a potential driver. Almost half of the organizations pointed out that a clear definition of responsibilities is critical for the overall effectiveness of the company. This was particularly important when a number of employees or departments are involved with one process: “... we model the process flow of the processes which are influenced by many organizational units...”(I9).

\subsubsection{Phenomenon}

A central event leads to the occurrence or development of the phenomenon, which is here the formed attitude of an organization towards BPM [18]. Besides the general attitude towards BPM, we identified two additional specific attitudes, namely, attitude towards modeling languages and modeling guidelines. Organizations believed that "Without a goal and purpose for the modeling initiative everything is difficult"(I10), implying that most often difficulties would arise with redundancy, overhead and lack of organizational improvement.

We found that almost all of the interviewed organizations tend to put strong emphasis on the process modeling language. Almost all chose or are planning to transfer to BPMN. The key reasons are either to be able to model the processes with high level of granularity, to transition to process automation or for easier identification of the process weaknesses "We use BPMN when we want to discuss the cutting points of the processes"(I9). This is usually practiced when a process goes 
through more than one department. What is more is that organizations of our interview partners put relevance on having clear modeling guidelines that each modeler will follow for later consistent process modeling, thus making the process models comprehensible for all "...because by having guidelines it is easier for the employees to read and understand the processes"(I8).

\subsubsection{Actions and Strategies}

Actions and Strategies are devised to manage, handle, carry out and respond to a phenomenon under a specific set of predefined causal conditions [18]. We categorized the actions and strategies we found organizations to be carrying out into seven subcategories: Modeling language, Modelers, Modeling guidelines, Process identification, Process start and end, Process model representation and Methods for ensuring process quality.

Compliant to the attitude towards modeling languages, we found that our interviewed organizations started modeling their processes with BPMN or planned to transition to it; "We moved from UML to BPMN"(I2). In addition, most of our interviewees compelled their employees to model the processes they are involved with, "Everybody in the company has to model"(I2). However, training in the respective modeling language is provided beforehand. Alternatively, when a process modeling expert is employed, we observed an interaction between the modelers and the employees, "The modeler who is responsible for the sales processes interacts with the employees of the sales department regularly in order to get to know the processes in detail"(I8).

Being confronted with complex processes, organizations need to decide in advance on a set of modeling guidelines in order to control potential process model complexity. Our data suggests that companies typically developed specific guidelines which need to be considered in this context. These guidelines define the range of elements modelers are allowed to use when modeling their business processes, "We have elements which are allowed to be used"(I6). Additionally, they defined the maximum number of elements one process model should not exceed, the model layout, the roles of each process, and their parts.

Moreover, we discovered a list of processes companies' model first. All eleven companies concentrated on modeling the processes they use on daily bases. Also, more than half started modeling the processes which needed improvement, "At the beginning, the processes which we knew needed an improvement, we tried to model them..."(I6). Some organizations started modeling those processes that reflect the company's strategy "What is important are the processes contributing to the company's strategy, goals, ...”(I10). In addition, we observed that organizations put emphasis on the start and end of one process. For most of our interviewees, this was based on the departments or employees involved. Hence, when more than one stakeholder is involved in the execution of a single process, they decomposed it accordingly, "Process ends when one department did its job, and another department needs to continue"(I11). Others do this depending on a customer perspective.

According to Indulska et al., the definition of an appropriate level of detail is ranked fifth on the scale of ten process modeling issues [7]. Other studies consider an 
end-to-end representation of processes imperative for better understanding among the stakeholders [19]. Our findings outlined that some companies tried to capture all details of the routine processes, "An end-to-end representation of the process is used when the process is a simple service that is used on daily basis, like customer orders"(I11). While others preferred a process model not to be decomposed if only one department is involved in its execution, “...so we don't decompose it [the process] if it is the same department that deals with the process, but model it until the end no matter how big and complex the process gets"(I9). In general, our data indicated the usefulness of decomposing a process model. It is considered as a more comprehensible way of representation when a process model has been decomposed in case the number of elements exceeds the specified number of elements allowed, "However, if the process gets too big, more than 15 elements, we try to decompose it"(I8). We also observed that most organizations ensured the accuracy of the process models by either using predefined steps for process approval, or depending on the decision of the process manager, "When the process model has been modeled by the two expert modelers, the process manager ensures the process is correct and decides on its approval"(I7).

\subsubsection{Outcome of BPM Adoption}

The consequences followed by the choice of actions lead to a set of various outcomes. Consistent with the reasons for adopting BPM, these outcomes can be classified into three categories: understanding of processes, performance of processes and control of processes. Ordinarily these should all be expected outcomes, mirrored to each initial reason for BPM adoption. However, we also observed some that were not anticipated by the organizations.

Our data showed that five organizations used the process models to train their employees, "This process is used as a manual of how the process works and what needs to be done"(I10), compared to only one stating this as a reason. Similarly, more organizations than those with clear expectations yielded process improvements, "We used them [the process models] mainly for faster processing of events, shortening of waiting periods in the processes..."(I4). BPM also appears to contribute to an easier definition of roles and responsibilities, "[The process models are used] to define what stakeholders each of the processes have"(I5). Moreover, we found that some organizations used the process models as a tool for easier approaching their customer demands in order to "avoid ignorance when new projects arrive, but go directly to solving"(I6).

\subsection{Business Process Modeling Pitfalls}

Based on the conceptual framework as well as some additional insights from our interview material, we were able to reference some of the pitfalls that Rosemann suggested as challenging for practitioners [11, 12].

Lack of Strategic Connection. The first pitfall implies the lack of demonstrable connection to one or more critical business issues [11]. According to Rosemann if an 
organization does not consider such connections, the initiative is considered as a form of "waste" and should be stopped [11]. We observed that organizations appear to be aware of their reasons for pursuing business process modeling. Almost half of our interviewees pointed out the importance of identifying the processes that define the company's strategy, "We first started to model the processes which we consider core, the most important for the company's strategy. So these 5-7 processes are our priority"(I7). Accordingly, they use BPM to better execute their corporate strategy.

Lack of Governance. A good governance system is necessary, as it aims towards effective communication and collaboration in an organization. There are few studies that proposed a set of principles for effective process governance, one of which points out the relevance of process prioritization $[3,20,21]$. It is suggested that a company should have an appointed BPM expert who makes the key decisions about the BPM implementation. These range from the decision of who will model the processes, the selection of the processes to be modeled, the level of granularity for each process model, etc. Our interviewees, being BPM experts themselves, clearly stated the emphasis they put on identification of the processes to be modeled first. This is done by prioritizing the processes the company considers as most important which sequentially leads to the commencement of a framework where the process models will be stored. Having established process governance is also important when the organization is planning to undertake some change. In line with that, we found that there are a number of companies that first modeled the processes they plan to automate, "...we are also starting to consider automation of the processes, so we are preparing the process models for future implementation as a workflow"(I9). In this way they aim to assure that the processes will be standardized and quality proved before they are transitioned to automation.

Additionally, Rosemann pointed out the lack of knowledge concerning the success of BPM adoption and how it is measured [11]. In order to address this point, we found that organizations formulated expectations of certain outcomes from the BPM adoption, compliant with their initial reasons. However, the frequencies of reasons and consequences in the conceptual framework reveal that organizations experienced certain expected outcomes, but also some unexpected beneficial outcomes, such as using the process models to clearly approach their customer demands, "Avoid ignorance when new projects arrive, but go directly to solving"(I6).

Lack of Synergies. Our data illustrated various reasons acting as triggers for BPM adoption. In addition, Rosemann argues that different departments within one organization are triggered by different purposes, consequently modeling the same process independently from each other [11]. Yet, our data suggests that some organizations were aware of this particular problem occurring. Accordingly, they applied specific strategies in order to avoid it. For instance, there are companies that get requests from their departments as to what processes they need to be modeled, "The processes which we identified to be modeled are those that the different departments need, processes in which we want to find the cutting points, which need optimization, and so on"(I5). Moreover, there are service providers integrating process modeling competence where appropriate, "We have an internal service 
provider ... and when the departments approach the provider with some problem, task, project, we consult them that it would be a good idea to do this or that."(I9).

Lack of Qualified Modelers. A business process analyst must be able to translate process documentation into structured process models [11]. According to Rosemann, practitioners mainly focus on explaining the modeling tool rather than training the modelers [11]. Our data suggested that the employees were trained in the respective modeling language in order to model the processes they are involved in. Some organizations employed process modeling experts or external consultants. This appeared to happen when a process needed to be modeled with a higher level of granularity because of a specific reason. Nonetheless, they usually collaborated with the employees involved with the processes, "....so the modeler who is responsible for modeling the sales processes interacts with the employees of the sales department regularly"(I8). This in turn helped capturing the correct flow of the processes. In addition, organizations used specified set of modeling guidelines. In this way, those companies that compelled their employees to model aimed to reduce the complexity of the modeling tool, "[Following the modeling guidelines] because it is easier for the employees who are beginners with BPMN to learn how to use it"(I2). Furthermore, acknowledging quality assurance as a part of the modeling process [11], we found that organizations used various steps to assure model quality, "After the processes have been modeled, we [the modelers] show the process models again to the employees from the different departments to verify them"(I9).

Lack of Realism. Our interview data emphasizes the importance of selecting the processes to be modeled first. The initial reasons for adopting BPM appear to be used as guidance for identifying the most relevant processes that will lead to the realization of their expected outcome. Besides that, we also found that companies did not allow loosing themselves in the vast amount of process models. Rather, they modeled only those processes they require for specific purpose, "We concentrate mainly on customer demands. So we don't just sit there and say 'ok, we have like 1000 processes so which ones do we model'" (I9).

Lack of Details. Rosemann discusses the limitations existing modeling languages offer and that they hardly satisfy the range of application areas the process models are used for [12]. Thus, organizations need to be aware of the language they choose for modeling their processes, as this language should be able to capture the required level of detail. Two things should be considered. First, modeling languages and tool functionality has advanced in the recent years. Second, it was emphasized that modeling languages were selected to best serve the purpose of the process models, "We used EPC because of staff requirement evaluation."(I9). In addition, many used BPMN to capture the technical process models "We started using BPMN 2.0 to direct ourselves to automation of the processes"(I5). Moreover, companies also decided on BPMN in order to be able to represent the processes with high level of granularity, “...companies transfer to BPMN 2.0 because they want to capture all details of the process"(I11).

L'Art pour l'Art. It is important to be clear of the purpose the process models have. This is primarily because the purpose of the model determines how detailed the 
process should be modeled. Rosemann argues that process models do not necessarily need to be complete, however they have to be relevant [12]. In line with that, we found that the modeling guidelines are used as a barrier for creating process models of inappropriate detail. This is based either on the relevance the organization puts on specific processes, or the requirements from the respective department. Thus, whereas one organization modeled those processes that go through more than one department detailed, others captured the entire process flow depending on the process type, "Customer processes are modeled almost 100\%"(I7).

\section{Conclusion}

In this paper we investigated BPM adoption and its relation to business process modeling pitfalls. We conducted eleven in-depth interviews with companies from various industries and qualitatively analyzed the data using Grounded Theory. We derived a conceptual framework integrating reasons for BPM adoption, the actions and strategies undertaken for its implementation, as well as the subsequent consequences. We found that organizations commence on the BPM initiative for better understanding, performance and control of processes. One of the main expected outcomes was that process models can be used to clearly allocate roles and responsibilities, especially when more departments are involved with a single process. Additionally, unanticipated outputs were discovered, one of which was that the process model helps to approach customer demands in a clearer way. Beyond that, we used the framework along with insights from our interview material to discuss some of the business process modeling pitfalls suggested by Rosemann [11, 12]. As a result we founded that organizations were aware of the BPM consequences, thus they selected the actions appropriately, based on their initial reasons for BPM adoption.

We identify as a limitation the small number of interviews made. At this stage, we did not ensure a conceptual saturation. Therefore, in future research we plan to increase the number of interviews by finding interview partners from various industries. Furthermore, we plan to broaden our interview guideline, aiming towards more insights of how oranizations are dealing with the pitfalls of business process modeling.

\section{References}

1. Kettinger, W., Teng, J., Guha, S.: Business process change: A Study of methodologies, techniques, and tools. MIS Quarterly 1(21), 55-80 (1997)

2. Reijers, H.A., Liman Mansar, S.: Best practices in business process redesign: an overview and qualitaive evaluation of successful redesign heuristics, pp. 283-306 (2005)

3. Bandara, W., Gable, G., Rosemann, M.: Factors and measures of business process modeling: model building through a multiple case study. European Journal of Information Systems, 347-360 (2005)

4. Petter, S., DeLone, W., McLean, E.: The Past, Present, and Future of "IS Success". Journal of the AIS, 341-362 (2012) 
5. Al-Mudimigh, A.: The role and impact of business process management in enterprise systems implementation. Business Process Management Journal 13, 866-874 (2007)

6. Reijers, H.A., van Wijk, S., Mutschler, B., Leurs, M.: BPM in Practice: Who Is Doing What? In: Hull, R., Mendling, J., Tai, S. (eds.) BPM 2010. LNCS, vol. 6336, pp. 45-60. Springer, Heidelberg (2010)

7. Indulska, M., Recker, J., Rosemann, M., Green, P.: Business Process Modeling: Current Issues and Future Challenges. In: van Eck, P., Gordijn, J., Wieringa, R. (eds.) CAiSE 2009. LNCS, vol. 5565, pp. 501-514. Springer, Heidelberg (2009)

8. Bandara, W., Guy, G., Rosemann, M.: Business Process Modeling Success: An Empirically Tested Measurement Model. In: Proc. Int. Conf. on Information Systems, pp.1-20 (2006)

9. Trkman, P.: The Critical Success Factors of Business Process Management. International Journal of Information Management, 125-134 (2010)

10. Bandara, W., Alibabaei, A., Aghdasi, M.: Means of achieving Business Process Management success factors. In: Proc. Mediterranean Conf. on Information Systems (2009)

11. Rosemann, M.: Potential pitfalls of process modeling: part A. Business Process Management Journal, 249-254 (2006)

12. Rosemann, M.: Potential pitfalls of process modeling: part B. Business Process Management Journal 12(3), 377-384 (2006)

13. Lee, A.: A scientific methodology for MIS case studies. Management Information Systems Quarterly, 32-50 (1989)

14. Yan, R.: Case study research methods, California (1994)

15. Williams, C.: Research Methods. J. of Business \& Economic Research 5(3), 65-72 (2007)

16. Creswell, J.: Research Design: Qualitative, Quantitative and Mixed Methods Approaches, 2nd edn. SAGE Publications, Thousand Oaks (2003)

17. Benbasat, I., Goldstein, D., Mead, M.: The Case Research Strategy in Studies of Information Systems. MIS Quarterly 11(3), 369-385 (1987)

18. Strauss, A., Corbin, J.: Basics of Qualitative Research: Grounded Theory Procedures and Techniques. SAGE Publications (1998)

19. Spanyi, A.: More for less: the power of process management. Meghan-Kiffer Press (2006)

20. de Bruin, T., Doebeli, G.: Progressing an Organizational Approach to BPM: Integrating Experience from Industry and Research. In: Proper, E., Harmsen, F., Dietz, J.L.G. (eds.) PRET 2009. LNBIP, vol. 28, pp. 34-49. Springer, Heidelberg (2009)

21. Richardson, C.: Process Governance Best Practices: Building a BPM Center of Excellence. BPTrends (2006) 